\title{
(2) OPEN ACCESS \\ Lower nationwide rates of arthroscopic procedures in 2016 compared with 1997 (634925 total arthroscopic procedures): has the tide turned?
}

\author{
Margit C Karelson (D) , Jarkko Jokihaara, ${ }^{2}$ Antti P Launonen, ${ }^{3}$ Tuomas Huttunen, ${ }^{4}$ \\ Ville M Mattila, 5
}

'Department of Hand and

Microsurgery, Tampere University Hospital, Tampere,

Finland

${ }^{2}$ Department of Hand and Microsurgery, Faculty of Medicine and Health Technology, Tampere University, Tampere University Hospital, Tampere, Finland

${ }^{3}$ Department of Orthopaedics and Traumatology, Tampere University Hospital, Tampere, Finland

${ }^{4}$ Department of Emergency, Anesthesia and Pain Medicine; Faculty of Medicine and Health Technology, Tampere University, Tampere University Hospital,

Tampere, Finland

${ }^{5}$ Faculty of Medicine and Health Technology; Department of Orthopaedics and Traumatology, Tampere University Hospital, Tampere University, Tampere, Pirkanmaa, Finland

${ }^{6}$ Coxa Hospital Ltd, Tampere,

Pirkanmaa, Finland

Correspondence to

Dr Margit C Karelson,

Department of Hand and Microsurgery, Tampere

University Hospital, Tampere 33520, Finland;

margit.karelson@gmail.com

Accepted 15 March 2020

Check for updates

(c) Author(s) (or their employer(s)) 2020. Re-use permitted under CC BY-NC. No commercial re-use. See rights and permissions. Published by BMJ.

To cite: Karelson MC, Jokihaara J,

Launonen $\mathrm{AP}$, et al.

Br I Sports Med Epub ahead of print: [please include Day Month Year]. doi:10.1136/ bisports-2019-101844

\section{ABSTRACT}

Objectives To assess the rates and secular trends of different joint arthroscopies — shoulder, elbow, wrist, hip, knee and ankle-in Finland between 1997 and 2016.

Design Retrospective nationwide registry study. Participants All adults in Finland with any arthroscopic intervention procedure code for knee, shoulder, ankle, wrist, elbow or hip arthroscopy between 1 January 1997 and 31 December 2016 were included.

Main outcome measures Incidence rate of arthroscopic surgery per 100000 person-years. Results The rate of knee and shoulder arthroscopies declined after reaching a peak in 2006 and 2007, respectively. The rates of wrist, elbow and hip joint arthroscopies declined after their 2014 peak. At the same time, the median age of patients who had knee, ankle and hip arthroscopy decreased, whereas the age of patients who had shoulder arthroscopy increased.

Conclusions Numerous randomised controlled trials point to lack of efficacy of the most common knee and shoulder arthroscopic procedures. It should not be assumed that this has contributed to decreased rates of arthroscopic surgery. The concurrent decrease in most of the other joint arthroscopic procedures was unexpected.

\section{INTRODUCTION}

Arthroscopic meniscectomy and debridement of the knee and subacromial decompression of the shoulder are common procedures in orthopaedic surgery, but the efficacy of these procedures has been questioned in randomised controlled trials. ${ }^{1-12}$ These trial results appear to have contributed to a lower rate of knee and shoulder arthroscopic procedures. $^{113}$

Arthroscopy for the ankle, elbow, wrist and hip are also quite common orthopaedic operations. ${ }^{14} 15$ Ankle arthroscopy is widely used for the diagnostic assessment and treatment of ankle impingement due to synovitis and/or degenerative osteophytes ankle instability, and osteochondral lesions. ${ }^{16} 17$ Arthroscopy of the elbow is used to treat osteochondral defects, loose bodies and arthrolysis. ${ }^{18}$ Wrist arthroscopy is widely used for the diagnosis and treatment of triangular fibrocartilage complex tears and ligament disruptions. ${ }^{16}{ }^{19}$ Hip arthroscopy indications have been expanded from intra-articular pathology in the native hip joint to perithrochanteric space disorders, paediatric hip disorders, trauma and hip snapping. ${ }^{20} 21$

The purpose of this study was to assess the rates and secular trends of all common joint arthroscopies of the shoulder, elbow, wrist, hip, knee and ankle performed in Finland between 1997 and 2016.

\section{METHODS}

All arthroscopic procedures performed between 1 January 1997 and the 31 December 2016 were included in the analysis (figure $1 \mathrm{~A}$ and $\mathrm{B}$ ). In addition, the results for each joint were analysed separately. Data on every operatively treated patient was obtained from the Finnish National Hospital Discharge Registry (NHDR). The Finnish NHDR, founded in 1967, provides data on patients' age, sex, duration of hospital stay, primary and secondary diagnoses and all operative treatments. Data reporting to the NHDR is mandatory for all public and private hospitals in Finland. The NHDR provides full nationwide coverage and the validity of its data has been found to be excellent in coverage and accuracy in describing the rates of surgical procedures. ${ }^{22-26}$

In this study, all patients in Finland aged 18 or older, with any surgical procedure code for knee, shoulder, ankle, wrist, elbow and hip arthroscopy (box 1) between 1 January 1997 and 31 December 2016 were included. The surgical procedures were coded according to the Finnish version of the Nordic Classification of Surgical Procedures (NCSP). The NCSP codes for arthroscopy procedures include diagnostic arthroscopy, debridement, capsulectomy, synovectomy and other specific treatments performed using the arthroscopic technique (box 1). All outpatients and hospitalised patients receiving surgery were included. The main outcome variable for the study was the incidence rate of arthroscopic surgery per 100000 person-years.

The study was reported according to the STROBE guidelines.

\section{STATISTICS}

To compute the incidence rates, the annual midpopulation was obtained from the Official Statistics of Finland, which is an electronic national population register (Official Statistics of Finland: Labour Force Survey, 2016). The rates for each year were not obtained from cohort-based estimates but from the whole national population, and therefore confidence intervals were not calculated.

\section{RESULTS}

The total number of arthroscopic procedures during the investigation period was 634925 . During the 

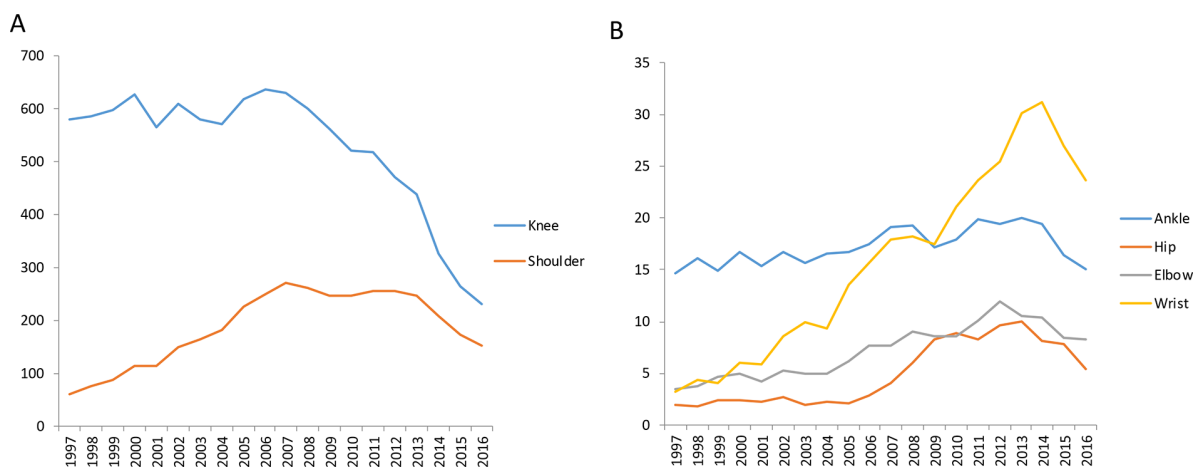

Figure 1 Rate of (A) knee and shoulder arthroscopies and (B) elbow, wrist, ankle and hip arthroscopies between 1997 and 2016 per 100000 person-years.

19-year study period, the adult population size of Finland grew from 3.979 million to 4.428 million.

\section{Knee}

The total number of knee arthroscopies was 438787 (women $\mathrm{n}=191782(43.7 \%)$, men $\mathrm{n}=247005$ (56.3\%)). Between 1997 and 2016, the annual median age decreased from 51 to 44 years in women and from 44 to 40 years in men. Knee joint arthroscopy procedures comprised $69 \%$ of all arthroscopies during the study period (figure 1). The overall rate for knee arthroscopy increased on average by $1.2 \%$ every year from the beginning of the study in 1997 until 2006 (from 579 to 636 per 100000 person-years (figure 1). After 2006, the rate decreased by twothirds-on average, 9.3\% every year (from 636 to 231 per 100000 person-years). During the whole study period, the incidence rate was highest for the 18-39 and 40-59 years age groups (figure 2). The most common procedures performed were partial excision of the meniscus (NGD05, 46.8\% of all knee arthroscopies) and exploration with debridement (NGA30, 16.7\% of all knee arthroscopies). The rate of partial excision of the meniscus and exploration with debridement decreased from the peak rates by $68 \%$ and $89 \%$, respectively. Only the rate for reinsertion of the meniscus (NGD25) increased over the study period.

\section{Shoulder}

The total number of shoulder arthroscopy procedures was 157918 (women $n=63553$ (40.2\%), men $n=94365$ (59.8\%)). Between 1997 and 2016, the median age for women increased from 48 to 53 years and from 43 to 52 years for men. The overall incidence rate for shoulder arthroscopy increased more than fourfold from the beginning of the study in 1997 to the peak rate in 2007. From the beginning of the study, the rate increased on average by $16.6 \%$ every year (from 60.4 to 271 per 100000 person-years) (figure 3). After 2007, the rate declined on average by $6.0 \%$ per year (from 271 to 152 per 100000 person-years). The incidence rate was highest for the 40-59 years age group for the whole study period (figure 3). The most common procedures were acromioplasty (NBG15, 50\% of all shoulder arthroscopy procedures) and exploration of the shoulder joint (NBA30, 18\% of all shoulder arthroscopy procedures). The rates of acromioplasty and exploration decreased by $52 \%$ and $80 \%$ from the peak rates to the end of the study period in 2016, respectively, and all incidence rates for different shoulder arthroscopic procedures decreased towards the end of the study period.
Ankle

The total number of ankle arthroscopy procedures was 14443 (women $\mathrm{n}=6557$ (45.4\%), men $\mathrm{n}=7886$ (54.6\%)). During the study period, the median age decreased for women from 45 to 41 years but remained at 40 years for men. The overall incidence rate for ankle arthroscopy had some yearly variation but no constant trends over time during the study period (figure 4). The incidence rates were similar for the 18-39 and 40-59 years age groups but lower for patients in the over 60 years age group. The most common procedures were debridement (NHF25, 61\% of all ankle arthroscopy procedures) and exploration (NHA30, $27 \%$ of all ankle arthroscopy procedures). The incidence rate for debridement remained constant over the study period, whereas the rate for exploration decreased by $27 \%$ from the peak rate in 2007.

\section{Wrist}

The total number of wrist arthroscopies was 13501 (women $\mathrm{n}=6756(50.0 \%)$, men $6745(50.0 \%))$. The median age at operation was 42 years for women and 40 years for men, with no change during the study period between 1997 and 2016. The incidence rate of wrist arthroscopy increased on average by $15 \%$ every year until 2014 (from 3.2 to 28.2 per 100000 personyears) (figure 5). After 2014, the rate declined on average by $4 \%$ every year (from 28.2 to 20.7 per 100000 person-years in 2016). The changes in incidence rate were similar in the 18-39 and 40-59 years age groups but lower for the over 60 years. Wrist exploration (NDA30, 57.8\% of all wrist arthroscopy procedures) and arthroscopic debridement for osteochondritis (NDF25, 36.8\% of all wrist arthroscopy procedures) were the two most common procedures. The incidence rate for wrist exploration decreased by $37 \%$ from the peak rate, but the rate of operation for osteochondritis continued to increase over the study period.

\section{Elbow}

The total number of elbow arthroscopies was 6069 (women $\mathrm{n}=1804(29.7 \%)$, men $\mathrm{n}=4265(70.3 \%))$. Median age at operation was 45 years for both sexes without any change during the study period. The overall incidence rate for elbow arthroscopy increased threefold from the beginning of the study period to the highest rate in 2012. Before 2012, the incidence rate increased on average by $8.6 \%$ every year (from 3.5 to 10.6 per 100000 person-years) (figure 6). However, after 2012, the rate declined on average by $9.1 \%$ annually (from 10.6 to 7.1 per 100000 person-years in 2016). The largest increase and decrease in 
Box 1 Codes for arthroscopic procedures according to the Finnish Nordic Classification of Surgical Procedures

\section{Knee}

NGA30 Arthroscopic exploration of knee joint NGD05 Arthroscopic partial excision of meniscus of knee NGD15 Arthroscopic total excision of meniscus of knee NGD25 Arthroscopic reinsertion of meniscus of knee NGE15 Arthroscopic incision of capsule of knee NGE25 Arthroscopic suture or reinsertion of ligament of knee, lateral collateral

NGE35 Arthroscopic plastic repair of ligament of knee not using prosthetic material, anterior cruciate

NGE45 Arthroscopic plastic repair of ligament of knee not using prosthetic material, posterior or posterior and anterior cruciate

NGE55 Arthroscopic plastic repair or reinsertion of cruciate and collateral ligaments of the knee

NGE65 Arthroscopic plastic repair of patellar ligaments NGF00 Arthroscopic excision of plica of synovia of knee NGF25 Arthroscopic operation for osteochondritis of knee

\section{Shoulder}

NBA30 Arthroscopic exploration of shoulder joint NBE15 Arthroscopic incision or suture of capsule of joint of shoulder

NBE25 Arthroscopic suture or reinsertion of ligament of shoulder

NBE35 Arthroscopic transposition of ligament of shoulder NBE45 Arthroscopic plastic repair of ligament of shoulder NBF15 Arthroscopic humeroscapular synovectomy NBF25 Arthroscopic operation for humeroscapular osteochondritis

\section{NBG15 Arthroscopic acromioplasty}

NBH98 Other arthroscopic operation on joint of shoulder NBL05 Arthroscopic suture or reinsertion of rotator cuff of shoulder

\section{Ankle}

NHA30 Arthroscopic exploration of joint of ankle or foot NHF15 Arthroscopic synovectomy of ankle NHF25 Arthroscopic operation for debridement of ankle joint

\section{Wrist}

NDA30 Arthroscopic exploration of joint of wrist or hand, NDE15 Arthroscopic incision or suture of capsule of joint of wrist or hand NDE25 Arthroscopic suture or reinsertion of ligament of wrist or hand

NDF15 Arthroscopic synovectomy of wrist

NDF25 Arthroscopic operation for osteochondritis of joint of wrist

\section{Elbow}

NCA30 Arthroscopic exploration of joint of elbow or forearm NCE10 Arthroscopic incision or deliberation of capsule of elbow joint

NCE25 Arthroscopic suture, reinsertion or transposition of ligament of elbow joint

NCF15 Arthroscopic synovectomy of elbow joint

NCF25 Arthroscopic operation for osteochondritis of elbow joint

NCH98 Arthroscopic other operation on elbow joint

\section{Box 1 Continued}

Hip

NFA30 Arthroscopic exploration of hip joint

NFF25 Arthroscopic debridement of hip joint

NFG00 Arthroscopic arthroplasty of hip joint

incidence rate was seen in the 40-59 years age group. Operations for osteochondritis (NCF25, 64.5\% of all elbow arthroscopy procedures) and exploration with debridement (NCA30, $25.3 \%$ of all elbow arthroscopy procedures) were the two most common procedures. The rate of operation for osteochondritis decreased by $34 \%$ from the peak year 2012, whereas the rate of operation for exploration with debridement remained constant over the study period.

\section{Hip}

The total number of hip arthroscopies was 4207 (women $n=1956$ (46.5\%), men $n=2251(53.5 \%))$. During the study period, the median age for women decreased from 47 to 37 years and from 50 to 32 years for men. The overall incidence rate for hip joint arthroscopy increased fivefold from the beginning of the study period to the highest rate in 2013. Before 2013, the rate had increased on average by $13.0 \%$ every year (from 1.9 in 1997 to 10.0 per 100000 person-years in 2012-2013) (figure 7). After 2013 however, the incidence rate declined on average by $17.9 \%$ every year (from 10.0 to 5.4 per 100000 person-years in 2016). The largest increases and decreases in the incidence rate were seen in the 18-39 and 40-59 years age groups. Arthroscopic debridement of the hip was the most common procedure (NFF25, 63.2\% of all hip joint arthroscopy procedures). After the peak year, the incidence rate decreased by $53 \%$ to the end of the study period in 2016

\section{DISCUSSION}

We believe this to be the first study that describes the populationbased national rates of all arthroscopic surgery of the six most commonly operated joints. Our main outcome was the rate of different joint arthroscopies over the study period, defined as the number of arthroscopies per 100000 person-years. First, the overall rate of knee and shoulder arthroscopies declined after the peak years of 2006 and 2007. This decline was expected because earlier high-quality trials had shown that the most

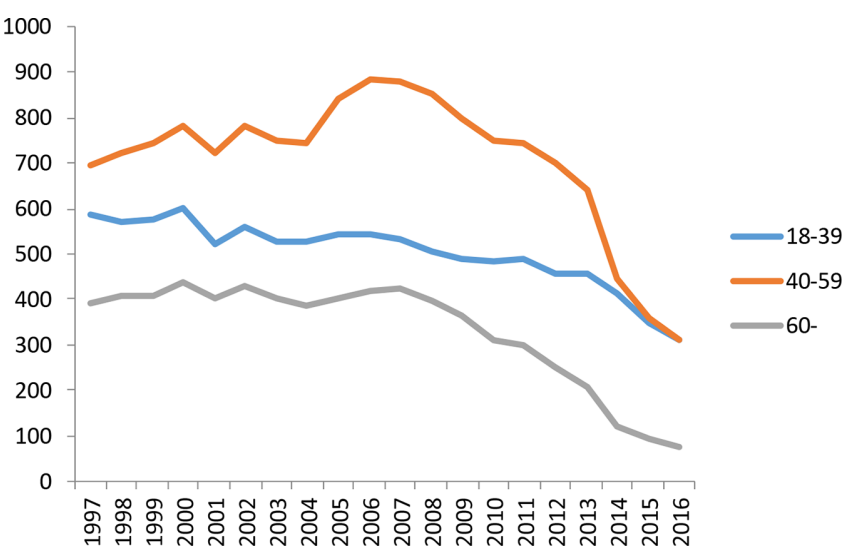

Figure 2 Rate of knee arthroscopy in different age groups per 100000 person-years. 


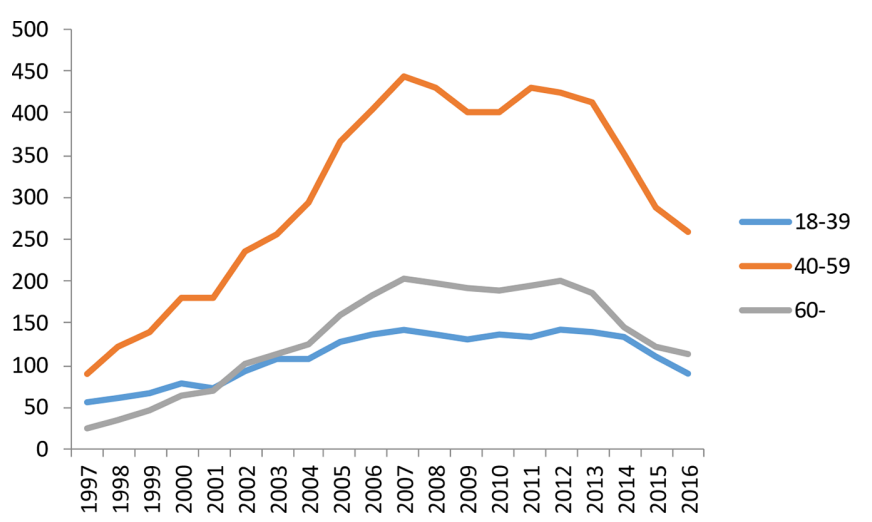

Figure 3 Rate of shoulder arthroscopy in different age groups per 100000 person-years.

common arthroscopic treatments for degenerative knee and shoulder diseases lacked efficacy in randomised controlled trial settings. ${ }^{19101327}$ Second, we observed an unexpected, latent (by 6-7 years), but parallel decline in the rates of wrist, elbow and hip joint arthroscopies. The rates of these arthroscopic operations peaked in the years 2012 and 2014. The median age of patients undergoing knee, ankle and hip arthroscopy decreased during the study period, whereas the median age of patients undergoing shoulder arthroscopy increased.

Why are there secular trends in knee arthroscopy?

Previous studies have reported trends in the incidence rates of knee arthroscopy. Kim et al reported a 49\% increase in the incidence of knee arthroscopies in the USA between 1996 and $2006{ }^{28}$ Mattila et al reported a decline in arthroscopies for degenerative knee disease after 2008 in Finland and Sweden, but that the incidence of arthroscopic meniscal resections for meniscal tears had increased. ${ }^{13}$ These results are in line with our findings that the rate for all knee arthroscopic operations increased every year until 2006 and thereafter decreased by two-thirds.

What caused these changes in knee arthroscopy? Between 1997 and 2014, multiple randomised controlled trials reported that arthroscopic debridement for the treatment of degenerative meniscal tear and osteoarthritis was ineffective. A US study by Moseley et al, based on a cohort from the Houston Veterans Affairs Medical Centre, and a Finnish multicentre study by Sihvonen et al both concluded that arthroscopic debridement or lavage was no better than a sham procedure for treating knee

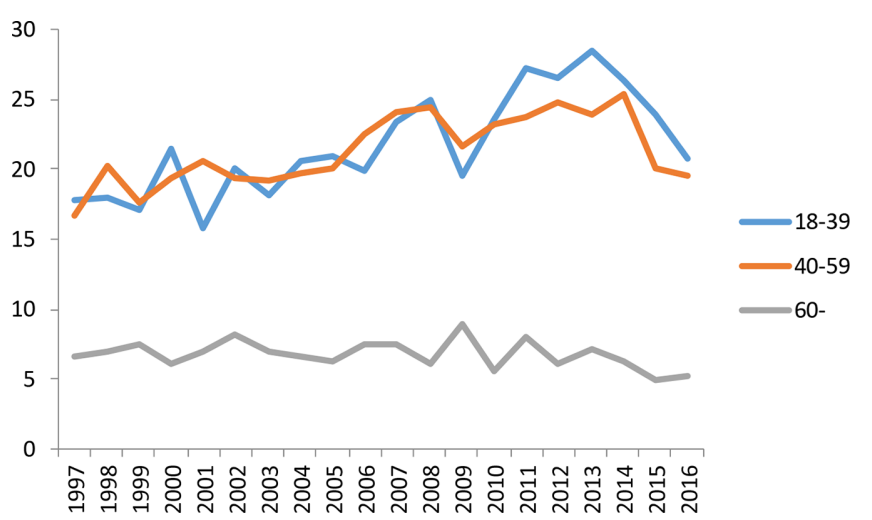

Figure 4 Rate of ankle arthroscopy in different age groups per 100000 person-years.

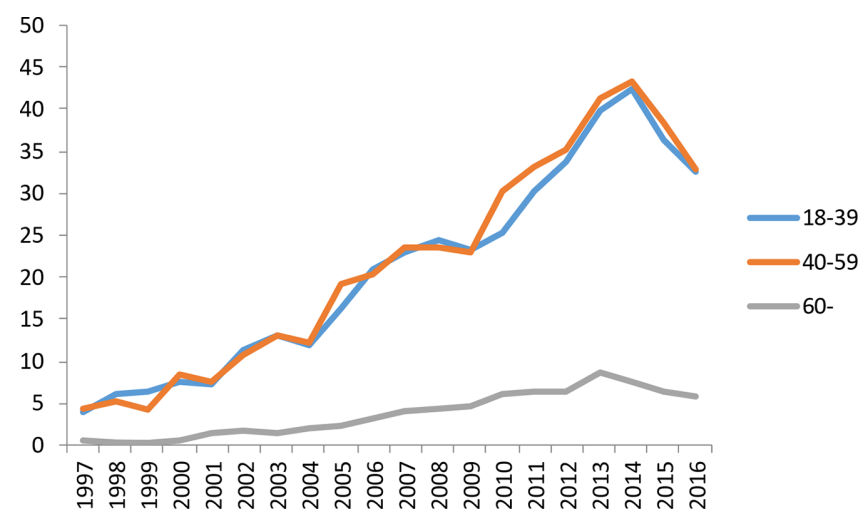

Figure 5 Rate of wrist arthroscopy in different age groups per 100000 person-years.

osteoarthrosis. ${ }^{6911}$ Also, Katz et al in the USA and the late Kirkley et al in Canada reported that arthroscopic surgery provided no additional benefit to physical therapy. ${ }^{2}{ }^{10}$ Gauffin et al in Sweden showed better results for arthroscopy in patients with meniscal symptoms at 1 year, but these results diminished over time. ${ }^{29}{ }^{30}$ In a UK cohort-based study, Abram et al reported that the incidence rates of arthroscopic knee washout and diagnostic arthroscopy declined between 1997 and 2017; they concluded that the change in surgical practice was a response among clinicians to the publication of evidence from clinical trials. ${ }^{31}$ Thus, the outcomes of these trials could have had an impact on the decrease in knee arthroscopy procedures seen in our results. The decrease detected may be considered beneficial, resulting in fewer surgical complications and cost savings, but whether the number of other surgical procedures, such as arthroplasties and other treatments, have changed is unknown.

Why are there secular trends in shoulder arthroscopy?

Rates of shoulder arthroscopy have also declined. In Finland, Paloneva et al previously reported an increased rate of acromioplasty between 1997 and 2007, followed by a decline of 20\% between the years 2007 and 2011. ${ }^{1}$ Our results show that this rate continued to decrease even though acromioplasty was still the most common procedure in our cohort. In another Finnish study, Kukkonen et al stated that there was no significantly or clinically important difference in outcome between three interventions (physiotherapy, acromioplasty and physiotherapy, and rotator cuff repair and physiotherapy) in the treatment of symptomatic, non-traumatic rotator cuff tears. ${ }^{32} 33$ A study by Bayle

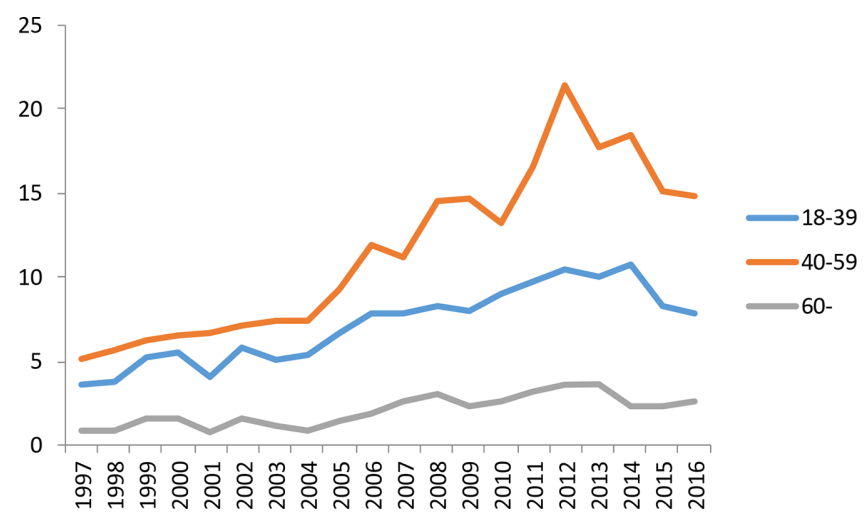

Figure 6 Rate of elbow arthroscopy in different age groups per 100000 person-years. 


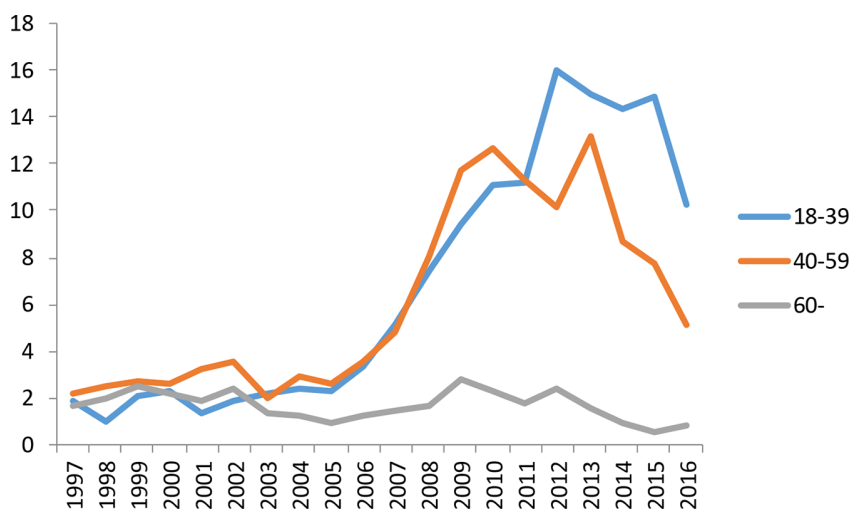

Figure 7 Rate of hip joint arthroscopy in different age groups per 100000 person-years.

et al in a French population compared open and arthroscopic rotator cuff repair and found no difference in clinical outcome or cuff integrity at the 1-year follow-up. ${ }^{7}$ A Finnish study by Paavola et al and the UK SEESAW study by Beard et al found that arthroscopic subacromial decompression provided no additional benefit over diagnostic arthroscopy in the treatment of shoulder impingement. ${ }^{812}$ Underlining these findings, systematic reviews and meta-analyses have provided high-quality evidence that shows the lack of efficacy in the repair of atraumatic, degenerative rotator cuff tears ${ }^{33-35}$ and acromioplasty. ${ }^{27} 35-37$

\section{Secular trends in ankle, wrist, elbow and hip arthroscopic surgery}

Over the past 25 years, ankle arthroscopy has evolved from anterior and posterior ankle arthroscopy to include also subtalar, talonavicular and first metatarsophalangeal joint arthroscopies. ${ }^{38}$ According to low-grade evidence based on case series and cohort studies, ${ }^{173940}$ ankle arthroscopy is recommended for the surgical treatment of anterior ankle impingement. This is in concordance with our results showing that debridement and synovectomy is the most common arthroscopic procedure performed on the ankle. There is a large spectrum of other suggested indications for arthroscopic techniques in the treatment of ankle instability, osteochondral lesions, osteoarthritis and fractures. ${ }^{17}$ 39-42 Although the practice of ankle arthroscopy seems well established and the rate remained constant in our results, we were unable to find any randomised controlled studies to support ankle arthroscopy procedures.

Wrist arthroscopy has been used as a diagnostic tool and increasingly as part of a therapeutic intervention. Every year, there has been an increase in the number of published studies on wrist arthroscopy. ${ }^{43}$ In our study, exploration of the wrist was the most common arthroscopic procedure, and the decrease in rate correlates with the increased use of MRI and CT as diagnostic tools in place of arthroscopy. ${ }^{43}$ In 2014, a systematic review identified four randomised studies that compared the arthroscopic wrist procedure with an open procedure. ${ }^{44}$ Leblebicioğlu et al compared open scaphocapitate fusion and revascularisation with the results of arthroscopic scaphocapitate fusion and capitate pole excision in the treatment of Kienböek disease and found in favour of the arthroscopic procedure. ${ }^{45}$ In a US study, Kang et al reported that there is no difference in recurrence between open and arthroscopic excision of the dorsal ganglion. ${ }^{46}$ Rocchi et al suggest arthroscopic resection of the volar ganglion as a reasonable alternative to open excision as it led to less postoperative morbidity and better cosmetic results. ${ }^{47}$ Some observational evidence also shows that arthroscopic assistance may provide additional benefit to the open surgery of intra-articular distal radius fractures ${ }^{48} 49$ and scaphoid waist fractures. ${ }^{50}$ Almost all wrist pathologies can be dealt with arthroscopically, but evidence that firmly supports the use of arthroscopy in wrist surgery is lacking. ${ }^{44}$

We were unable to identify any randomised controlled trials of the efficacy of elbow arthroscopy. Publications describe clinical outcomes of patient cohorts--such as the series of elbow arthroscopic debridement surgery performed on patients with primary or post-traumatic osteoarthritis, ${ }^{51}$ and osteochondritis dissecans and posterior impingement. ${ }^{52-55}$ Only case reports and expert opinions on several elbow pathologies suggest the use of arthroscopic procedures in evaluation and treatment. ${ }^{1856-60}$ In a US study, Leong et al assessed demographic trends in arthroscopic elbow surgery and found that the incidence increased from 1.27 in 10000 orthopaedic patients in 2007 to 1.45 in 10000 patients in $2011 .{ }^{14}$ The database used in the study included information from four American states. These results mirror the findings of our study, which show that the rate of elbow arthroscopic procedures increased until 2012.

According to the literature, arthroscopic hip surgery is safe but evidence of long-term efficacy is limited. ${ }^{61}$ Despite the limited evidence, over 50000 hip arthroscopies were performed annually in the USA between 2005 and $2013 .{ }^{61}{ }^{62}$ In addition, the number of procedures performed annually in England between 2002 and 2013 increased by $727 \%,{ }^{63}$ which is in agreement with our results. Some randomised controlled studies have compared hip arthroscopic surgery with physiotherapy in the treatment of femoroacetabular impingement (FAI). ${ }^{616465}$ In their US study, Mansell et al reported no difference between arthroscopic hip surgery and physiotherapy in the treatment of FAI at any time up to the 2-year follow-up. ${ }^{65}$ However, Palmer et al in a UK study found that patients with symptomatic FAI experience a greater improvement in symptoms after arthroscopic hip surgery than with physiotherapy and activity modification 8 months after randomisation. ${ }^{61}$ According to a systematic review and a randomised controlled study by Griffin et al in the UK, hip arthroscopy is a safe and effective procedure for the treatment of labral tears and FAI when performed on patients without significant underlying arthrosis and significantly improves quality of life. ${ }^{6466}$

Ferlie et al have proposed that the combination of scientific, organisational and behavioural factors drives changes in clinical practice. ${ }^{67}$ The possible scientific factors that could influence clinical practice include high-quality evidence-for example, randomised clinical trials. The decreasing rates of some common knee and shoulder arthroscopic operations can be explained by recent evidence showing the lack of efficacy of these operations. $^{26-81012}$ To date, however, there have been no clinical trial reports that explain why the rates of wrist, elbow and hip arthroscopy procedures are also decreasing. Organisational factors that could affect the rate of arthroscopic procedures are most commonly due to economic scrutiny and the increased demand for the cost-effectiveness of healthcare interventions. Moreover, it is also possible that the decreasing rates of arthroscopic operations reflect a growing awareness that many of the indications for these operations are unfounded. With regard to Finland, the guidelines for primary care physicians treating knee and shoulder osteoarthritis have been updated during recent years, with the result that patients are probably more often guided to physiotherapy than previously. Therefore, one possible behavioural factor could be the lack of conviction in the efficacy of many arthroscopic procedures performed on 
different joints. The number of Finnish orthopaedic surgeons is small (about 500), and thus treatment policies may spread across the country quite rapidly. Furthermore, educational programmes are compact, and information is disseminated effectively. Also, the imaging of joints with MRI and CT has become more available and accurate, and therefore pathologies can be diagnosed without explorative arthroscopy.

We have no firm explanations as to why the patient population has a younger age than before. One possible explanation could be that arthroscopic procedures for degenerative diseases in older patients have been shown to lack efficacy, and thus the rates of procedures are falling, but surgeons still tend to perform procedures for younger patients.

Surgical interventions demand high resources, and changes in the rates of arthroscopic operations can also be measured in terms of direct costs. Thus, the observed difference in the number of operations between the peak years and current rates of arthroscopic exploration of the knee joint (NGA30) and meniscectomy (NGD05) would cost in the region of $€ 850000$ $(£ 792000)$ per 100000 person-years if estimated at current prices (public prices in Finland for these common operations range on average from $€ 2000$ to $€ 3000$ euros ( $£ 1700$ to $£ 2800$ ). Similarly, the difference between the peak years and the current rates of the two most common shoulder arthroscopic operations, exploration (NBA30) and acromioplasty (NBG15), equals direct costs of $€ 350000$ ( $£ 326000$ ) per 100000 person-years. The direct costs of less common arthroscopic operations are lower, but they too have been under economic scrutiny. In a cost-effectiveness analysis, the indirect costs and relative costs of alternative treatment options should also have been included, but this would have been outside the scope of this study.

The strength of our study is the use of a validated nationwide database. In previous studies, the coverage and accuracy of the data in the Finnish NHDR have been found to be over $90 \%$. $^{23} 25$ The study population comprised the entire Finnish population and included all healthcare institutions. Thus, the results of the study describe the actual surgical practice in Finland. Consequently, the changes in the rates accurately show the change in surgical practice in Finland and reflect the general opinion among surgical practice because a universal healthcare system provides all surgical treatment equally to everyone in Finland.

There are some limitations with the Finnish NHDR, particularly the use of International Classification for Diseases (ICD) codes for diagnoses, which are often too vague for specific joint diseases. This prevents further analysis of the changes in the treatment of different joint conditions. Therefore, the indications and diagnoses were not taken into consideration owing to challenges in

\section{What are the new findings?}

- The rates of knee and shoulder arthroscopies declined after peaking in 2006 and 2007, respectively.

- The rates of wrist, elbow and hip joint arthroscopies have declined after 2012-2014 without a clear reason.

\section{How might it impact on clinical practice in the near} future?

- Our study suggests that 'real life' clinical practice is following the evidence of randomised controlled trials and data synthesis but unbiased experts. confirming the exact code and diagnosis from the registry. Also, the coding does not include the laterality of the limb, and thus it is not possible to evaluate whether the patient has had right or left limb operations separately or has had several arthroscopies of the same joint.

In conclusion, we observed declining rates in all of the most common arthroscopic procedures of different joints. After several high-quality studies, surgeons have perceived lack of efficacy of the most common knee and shoulder arthroscopic procedures, which probably accounts for the subsequent decrease in rates. However, the concurrent decrease in most of the other joint arthroscopic procedures was unexpected and not readily explicable.

Contributors On behalf of all authors, the corresponding author grants a worldwide licence to the publishers and its licensees in perpetuity, in all forms, formats and media (whether known now or created in the future), to (i) publish, reproduce, distribute, display and store the contribution; (ii) translate the contribution into other languages, create adaptations, reprints, include within collections and create summaries, extracts and/or, abstracts of the contribution; (iii) create any other derivative work(s) based on the contribution; (iv) to exploit all subsidiary rights in the contribution; v) include electronic links from the contribution to third party material wherever it may be located; and (vi) license any third party to do any or all of the above.

Funding The authors have not declared a specific grant for this research from any funding agency in the public, commercial or not-for-profit sectors.

Competing interests None declared.

Patient and public involvement Patients and/or the public were not involved in the design, or conduct, or reporting, or dissemination plans of this research.

Patient consent for publication Not required.

Provenance and peer review Not commissioned; externally peer reviewed.

Data availability statement Data are available upon reasonable request. Data may be obtained from a third party and are not publicly available. We agree on data sharing to British Journal of Sports Medicine when required according to the World Health Organization and Nordic Trial Alliance declaration about clinical trial transparency.

Open access This is an open access article distributed in accordance with the Creative Commons Attribution Non Commercial (CC BY-NC 4.0) license, which permits others to distribute, remix, adapt, build upon this work non-commercially, and license their derivative works on different terms, provided the original work is properly cited, appropriate credit is given, any changes made indicated, and the use is non-commercial. See: http://creativecommons.org/licenses/by-nc/4.0/.

\section{ORCID iD}

Margit C Karelson http://orcid.org/0000-0002-0101-9497

\section{REFERENCES}

1 Paloneva J, Lepola V, Karppinen J, et al. Declining incidence of acromioplasty in Finland. Acta Orthop 2015;86:220-4

2 Katz JN, Brophy RH, Chaisson CE, et al. Surgery versus physical therapy for a meniscal tear and osteoarthritis. N Eng/ J Med Overseas Ed 2013;368:1675-84.

3 Thorlund JB, Englund M, Christensen R, et al. Patient reported outcomes in patients undergoing arthroscopic partial meniscectomy for traumatic or degenerative meniscal tears: comparative prospective cohort study. BMJ 2017;356:j356.

4 Thorlund JB, Juhl CB, Roos EM, et al. Arthroscopic surgery for degenerative knee: systematic review and meta-analysis of benefits and harms. Br J Sports Med 2015;49:1229-35.

5 Khan M, Evaniew N, Bedi A, et al. Arthroscopic surgery for degenerative tears of the meniscus: a systematic review and meta-analysis. Can Med Assoc J 2014;186:1057-64.

6 Sihvonen R, Paavola M, Malmivaara A, et al. Arthroscopic partial meniscectomy versus sham surgery for a degenerative meniscal tear. N Engl J Med 2013;369:2515-24.

7 Bayle X, Pham T-T, Faruch M, et al. No difference in outcome for open versus arthroscopic rotator cuff repair: a prospective comparative trial. Arch Orthop Trauma Surg 2017;137:1707-12.

8 Beard DJ, Rees JL, Cook JA, et al. Arthroscopic subacromial decompression for subacromial shoulder pain (CSAW): a multicentre, pragmatic, parallel group, placebocontrolled, three-group, randomised surgical trial. The Lancet 2018;391:329-38.

9 Moseley JB, O'Malley K, Petersen NJ, et al. A controlled trial of arthroscopic surgery for osteoarthritis of the knee. N Engl J Med 2002;347:81-8.

10 Kirkley A, Birmingham TB, Litchfield RB, et al. A randomized trial of arthroscopic surgery for osteoarthritis of the knee. N Engl J Med 2008;359:1097-107. 
11 Sihvonen R, Paavola M, Malmivaara A, et al. Arthroscopic partial meniscectomy versus placebo surgery for a degenerative meniscus tear: a 2-year follow-up of the randomised controlled trial. Ann Rheum Dis 2018;77:188-95.

12 Paavola M, Malmivaara A, Taimela S, et al. Subacromial decompression versus diagnostic arthroscopy for shoulder impingement: randomised, placebo surgery controlled clinical trial. BMJ 2018;362:k2860.

13 Mattila VM, Sihvonen R, Paloneva J, et al. Changes in rates of arthroscopy due to degenerative knee disease and traumatic meniscal tears in Finland and Sweden. Acta Orthop 2016:87:5-11.

14 Leong NL, Cohen JR, Lord E, et al. Demographic trends and complication rates in arthroscopic elbow surgery. Arthroscopy 2015;31:1928-32.

15 Matsuura T, Egawa H, Takahashi M, et al. State of the art: elbow arthroscopy: review of the literature and application for osteochondritis dissecans of the capitellum. J Med Invest 2014;61:233-40.

16 Treuting R. Minimally invasive orthopedic surgery: arthroscopy. Ochsner J 2000;2:158-63.

17 Vega J, Dalmau-Pastor M, Malagelada F, et al. Ankle arthroscopy: an update. J Bone Joint Surg Am 2017;99:1395-407.

18 Nowotny J, Löbstein S, Biewener A, et al. Elbow arthroscopy in children and adolescents: analysis of outcome and complications. Eur J Med Res 2018;23:42-018 0338-5.

19 Slutsky DJ. Current innovations in wrist arthroscopy. J Hand Surg Am 2012;37:1932-41.

20 Jamil M, Dandachli W, Noordin S, et al. Hip arthroscopy: indications, outcomes and complications. Int J Surg 2018;54:341-4.

21 Ross JR, Larson CM, Bedi A. Indications for hip arthroscopy. Sports Health 2017;9:402-13.

22 Mattila VM, Huttunen TT, Haapasalo $\mathrm{H}$, et al. Declining incidence of surgery for Achilles tendon rupture follows publication of major RCTs: evidence-influenced change evident using the Finnish registry study. Br J Sports Med 2015;49:1084-6.

23 Huttunen TT, Kannus P, Pihlajamäki H, et al. Pertrochanteric fracture of the femur in the Finnish national hospital discharge register: validity of procedural coding, external cause for injury and diagnosis. BMC Musculoskelet Disord 2014;15.

24 Heinänen $M$, Brinck T, Handolin L, et al. Accuracy and coverage of diagnosis and procedural coding of severely injured patients in the Finnish hospital discharge register: comparison to patient files and the Helsinki trauma registry. Scand J Surg 2017:106:269-77.

25 Mattila VM, Sillanpää P, livonen T, et al. Coverage and accuracy of diagnosis of cruciate ligament injury in the Finnish national hospital discharge register. Injury 2008;39:1373-6.

26 Sund R. Quality of the Finnish hospital discharge register: a systematic review. Scand J Public Health 2012:40:505-15.

27 Lähdeoja T, Karjalainen T, Jokihaara J, et al. Subacromial decompression surgery for adults with shoulder pain: a systematic review with meta-analysis. $\mathrm{Br}$ I Sports Med 2019. doi:10.1136/bjsports-2018-100486. [Epub ahead of print: 15 Jan 2019].

$28 \mathrm{Kim} \mathrm{S}$, Bosque J, Meehan JP, et al. Increase in outpatient knee arthroscopy in the United States: a comparison of national surveys of ambulatory surgery, 1996 and 2006. J Bone Joint Surg Am 2011:93:994-1000.

29 Gauffin H, Tagesson S, Meunier A, et al. Knee arthroscopic surgery is beneficial to middle-aged patients with meniscal symptoms: a prospective, randomised, singleblinded study. Osteoarthritis Cartilage 2014;22:1808-16.

30 Gauffin $\mathrm{H}$, Sonesson S, Meunier A, et al. Knee arthroscopic surgery in middle-aged patients with meniscal symptoms: a 3-year follow-up of a prospective, randomized study. Am J Sports Med 2017;45:2077-84.

31 Abram SGF, Judge A, Beard DJ, et al. Temporal trends and regional variation in the rate of arthroscopic knee surgery in England: analysis of over 1.7 million procedures between 1997 and 2017. has practice changed in response to new evidence? Br J Sports Med 2019;53:1533-8.

32 Kukkonen J, Joukainen A, Lehtinen J, et al. Treatment of nontraumatic rotator cuff tears: a randomized controlled trial with two years of clinical and imaging follow-up. J Bone Joint Surg Am 2015;97:1729-37.

33 Kukkonen J, Joukainen A, Lehtinen J, et al. Treatment of non-traumatic rotator cuff tears: a randomised controlled trial with one-year clinical results. Bone Joint J 2014:96-B:75-81.

34 Piper CC, Hughes AJ, Ma Y, et al. Operative versus nonoperative treatment for the management of full-thickness rotator cuff tears: a systematic review and metaanalysis. J Shoulder Elbow Surg 2018;27:572-6.

35 Ryösä A, Laimi K, Äärimaa V, et al. Surgery or conservative treatment for rotator cuff tear: a meta-analysis. Disabil Rehabil 2017;39:1357-63.

36 Paloneva J, Lepola V, Äärimaa V, et al. Increasing incidence of rotator cuff repairs-a nationwide registry study in Finland. BMC Musculoskelet Disord 2015;16:189-0150639-6.

37 Mazuquin BF, Wright AC, Russell S, et al. Effectiveness of early compared with conservative rehabilitation for patients having rotator cuff repair surgery: an overview of systematic reviews. Br J Sports Med 2018;52:111-21.

38 Shimozono Y, Seow D, Kennedy JG, et al. Ankle arthroscopic surgery. Sports Med Arthrosc Rev 2018:26:190-5.
39 Zwiers R, Wiegerinck Jl, Murawski CD, et al. Arthroscopic treatment for anterior ankle impingement: a systematic review of the current literature. Arthroscopy 2015;31:1585-96.

40 Ross KA, Murawski CD, Smyth NA, et al. Current concepts review: arthroscopic treatment of anterior ankle impingement. Foot Ankle Surgery 2017;23:1-8.

41 Zekry M, Shahban SA, El Gamal T, et al. A literature review of the complications following anterior and posterior ankle arthroscopy. Foot Ankle Surg 2019;25:553558.

42 Chen X-Z, Chen Y, Liu C-G, et al. Arthroscopy-assisted surgery for acute ankle fractures: a systematic review. Arthroscopy 2015;31:2224-31.

43 Obdeijn MC, Tuijthof GJM, van der Horst CMAM, et al. Trends in wrist arthroscopy. $J$ Wrist Surg 2013;2:239-46.

44 Tadjerbashi K, Rosales RS, Atroshi I. Intervention randomized controlled trials involving wrist and shoulder arthroscopy: a systematic review. BMC Musculoskelet Disord 2014:15:252-2474-15-252.

45 Leblebicioğlu G, Doral MN, Atay A ö Ahmet, et al. Open treatment of stage III Kienböck's disease with lunate revascularization compared with arthroscopic treatment without revascularization. Arthroscopy 2003;19:117-30.

46 Kang L, Akelman E, Weiss A-PC. Arthroscopic versus open dorsal ganglion excision: a prospective, randomized comparison of rates of recurrence and of residual pain. $J$ Hand Surg Am 2008;33:471-5.

47 Rocchi L, Canal A, Fanfani F, et al. Articular ganglia of the volar aspect of the wrist: arthroscopic resection compared with open excision. A prospective randomised study. Scand J Plast Reconstr Surg Hand Surg 2008:42:253-9.

48 Varitimidis SE, Basdekis GK, Dailiana ZH, et al. Treatment of intra-articular fractures of the distal radius: fluoroscopic or arthroscopic reduction? J Bone Joint Surg $\mathrm{Br}$ 2008;90:778-85.

49 Mulders MAM, Selles CA, Colaris JW, et al. Operative treatment of intra-articular distal radius fractures with versus without arthroscopy: study protocol for a randomised controlled trial. Trials 2018;19:84-017-2409-2.

50 Clementson M, Jørgsholm P, Besjakov J, et al. Conservative treatment versus arthroscopic-assisted screw fixation of scaphoid waist fractures--a randomized trial with minimum 4-year follow-up. J Hand Surg Am 2015:40:1341-8.

51 Karelson M, Launonen AP, Jokihaara J, et al. Pain, function, and patient satisfaction after arthroscopic treatment of elbow in a retrospective series with minimum of 5year follow-up. J Orthop Surg 2019;27:230949901983280.

52 Adams JE, King GJW, Steinmann SP, et al. Elbow arthroscopy: indications, techniques, outcomes, and complications. J Am Acad Orthop Surg 2014;22:810-8.

53 Schoch B, Wolf BR. Osteochondritis dissecans of the capitellum: minimum 1-year follow-up after arthroscopic debridement. Arthroscopy 2010;26:1469-73.

54 Rahusen FTG, Brinkman J-M, Eygendaal D, et al. Results of arthroscopic debridement for osteochondritis dissecans of the elbow * commentary. Br J Sports Med 2006; 40:966-9.

55 Rahusen FTG, Brinkman J-M, Eygendaal D. Arthroscopic treatment of posterior impingement of the elbow in athletes: a medium-term follow-up in sixteen cases. J Shoulder Elbow Surg 2009;18:279-82.

56 Sochacki KR, Jack RA, Hirase T, et al. Arthroscopic debridement for primary degenerative osteoarthritis of the elbow leads to significant improvement in range of motion and clinical outcomes: a systematic review. Arthroscopy 2017;33:2255-62.

57 Soojian MG, Kwon YW. Elbow arthritis. Bull NYU Hosp Jt Dis 2007;65:61-71.

58 Vincent JI, Vandervoort AA, MacDermid JC. A literature synthesis indicates very low quality, but consistent evidence of improvements in function after surgical interventions for primary osteoarthritis of the elbow. Arthritis 2013;2013:487615

59 Wysocki RW, Cohen MS. Primary osteoarthritis and posttraumatic arthritis of the elbow. Hand Clin 2011:27:131-7.

60 Yeoh KM, King GJW, Faber KJ, et al. Evidence-based indications for elbow arthroscopy. Arthroscopy 2012;28:272-82.

61 Palmer AJR, Ayyar Gupta V, Fernquest S, et al. Arthroscopic hip surgery compared with physiotherapy and activity modification for the treatment of symptomatic femoroacetabular impingement: multicentre randomised controlled trial. BMJ 2019:9:1185

62 Maradit Kremers H, Schilz SR, Van Houten HK, et al. Trends in utilization and outcomes of hip arthroscopy in the United States between 2005 and $2013 . J$ Arthroplasty 2017:32:750-5.

63 Palmer AJR, Malak TT, Broomfield J, et al. Past and projected temporal trends in arthroscopic hip surgery in England between 2002 and 2013. BMJ Open Sport Exerc Med 2016;2:e000082.

64 Griffin DW, Kinnard MJ, Formby PM, et al. Outcomes of hip arthroscopy in the older adult: a systematic review of the literature. Am J Sports Med 2017;45:1928-36.

65 Mansell NS, Rhon DI, Marchant BG, et al. Two-year outcomes after arthroscopic surgery compared to physical therapy for femoracetabular impingement: a protocol for a randomized clinical trial. BMC Musculoskelet Disord 2016;17:60.

66 Griffin DR, Dickenson EJ, Wall PDH, et al. Hip arthroscopy versus best conservative care for the treatment of femoroacetabular impingement syndrome (UK fashion): a multicentre randomised controlled trial. Lancet 2018;391:2225-35.

67 Ferlie E, Wood M, Fitzgerald L. Some limits to evidence-based medicine: a case study from elective orthopaedics. Qual Health Care 1999:8:99-107. 